\title{
Selecting successful students? Undergraduate grades as an admission criterion
}

\author{
Adrian Chadi and Marco de Pinto \\ Institute for Labour Law and Industrial Relations in the European Union (IAAEU), University of Trier, Trier, Germany
}

\begin{abstract}
In Europe's reformed education system, universities may be forced by law to consider undergraduate grade point average (UGPA) as the primary admission criterion in the selection of graduate students. In this article, we investigate whether UGPA predicts graduate student performance in order to discuss its usefulness as an admission criterion. In our theoretical framework, we show that undergraduate students may choose slower study progress in favour of receiving higher grades and conclude that UGPA is a relatively good (weak) predictor for graduate grade point average (study progress). Having data from a cohort of students whose selection was in clear conflict with the legal requirement, we empirically confirm our theoretical predictions by exploiting a unique opportunity for assessing educational policies. Discussion of our findings leads to some important conclusions concerning the Bologna reforms and the lawmakers' idea of giving some independence to universities, but not too much of it.
\end{abstract}

\section{KEYWORDS}

Educational policies: graduate student selection; economics and law; time preferences; academic performance; student's utility; study progress

JEL CLASSIFICATION 128; 121; K42
Effective admission procedures are a critical component of an institution's ability to fulfill its mission and goals, and on a greater scale, of the capacity of tertiary education to contribute to a nation's economic and social goals. 'University Admission Worldwide' (Helms 2008)

\section{Introduction}

In the economic analysis of universities and higher education, the selection of graduate students has received only little attention from economists so far. The novelty of the topic could explain this lack of research. As a key element of the so-called Bologna reforms, European universities have received a new privilege to select their own graduate (master) students out of applicants with undergraduate (bachelor) degrees. While this concept is often perceived as a large step towards more autonomous universities, the legal framework established upon the ideals of the Bologna reforms actually intervenes heavily in the autonomy of universities by enforcing undergraduate grade point average (UGPA) as the primary admission criterion in the selection of graduate students. Without such legal intervention, universities could choose more freely between those potential admissions criteria that have been shown to be valid predictors of student performance in previous studies (e.g. Kuncel, Credé, and Thomas 2007).

Inspired by this legal intervention, we see a strong need for research concerning the suitability of using UGPA as the primary admission criterion in the new European system of higher education. Intuitively, if UGPA would not be able to predict students' performances in graduate programmes very well, one might expect several kinds of negative implications resulting from the legal intervention. Referring to the introductory quote above, not selecting their students of choice not only affects universities, costs for society are also likely to emerge. To empirically investigate a problem within a given legal framework, one theoretically needs to withdraw the law that is of concern in order to examine the counterfactual situation. The opportunity that we instead exploit is actual legal disobedience. Having data from an unprecedented case, our article reveals potential drawbacks of legally enforcing UGPA as an admission criterion by investigating how well this factor predicts graduate student performance.

A key aspect of our study is to consider graduate student success and thus the success of the admission 
process not only in terms of grades. As large numbers of students in many countries do not complete their programmes in the required period of time (see e.g. Brunello and Winter-Ebmer 2003), we argue that better performers not only have better grades but achieve these in less time than other students. Therefore, we question whether using UGPA as admission criterion leads to a successful selection of students in both performance dimensions, i.e. achieving high grades and high study progress in the graduate programme. Such an expanded definition of academic performance conforms to the recent development in the debate on higher education since researchers and policymakers increasingly realize that grades constitute only one dimension of academic success. Hence, by proposing study progress as a second performance dimension, we can on the one hand refer to an increasing amount of scientific research on the 'worldwide concern' of prolonged study time (Garibaldi et al. 2012). ${ }^{1}$ On the other hand, we take into account the political realm, where policy advisors and government councils also realize that there is a problem and are discussing ways to increase study speed. ${ }^{2}$

There are several reasons why prolonged study time is of concern. Delays in studying constitute a negative signal to the labour market, according to Brunello, Lucifora, and Winter-Ebmer $(2004,1128)$. Their large-scale survey among European students found that about half of the students expect to need more semesters than the formal number required to complete their degree. Closely related is the phenomenon of reduced later earnings from having a gap between high school and university and thereby postponing degree completion (Holmlund, Liu, and Skans 2008). From a social perspective, the labour market misses out on a well-qualified labour force of students who are instead absent and thus not as productive as they potentially could be. While spending additional time in a study programme does not necessarily increase qualification, it also implies costs to the providers of education (see e.g. OECD 2013), which in many countries are taxpayer-funded institutions. Therefore, not only universities suffer from additional completion delays with respect to capacities and overall costs but society as a whole suffers from the delayed introduction of potentially well-qualified labour.

We base the empirical investigation upon testable hypotheses concerning the predictive power of UGPA for average grades and study progress in the master programme. To that end, propositions about the determinants of our two performance measures and about their relationship to each other are needed. Therefore, we build a simple theoretical model in which decisions of utility-maximizing individuals during their studies are described. To be concrete, heterogeneous individuals can choose their level of learning effort and the number of exams per period they plan to complete. The former positively influences the average grade, while the latter determines progress.

The key finding of our theoretical framework is that a trade-off between average grades and study progress can arise. For some students, it is utilitymaximizing to provide a relatively high effort (and thus obtain relatively high average grades), but this comes along with a lower number of exams (and thus a relatively slow study progress). Hence, it is theoretically possible that students with high average grades do not fulfil the performance criterion of completing their studies quickly. As a result, our theoretical considerations establish hypotheses that elicit concerns regarding the predictive power of UGPA for graduate students' performance.

\footnotetext{
'Being a key facet of the discussion in our article, the concern about study progress is certainly country-specific, as shown by Brunello and Winter-Ebmer (2003). In Italy, for instance, there is broad discussion on how to shorten time to degree. See Aina, Baici, and Casalone (2011), who provide a comprehensive analysis of the determinants of study time based on Italian data. Also see De Paola and Gioia (2017) as well as De Paola and Scoppa (2015), who analyse study progress measured in credits per semester. Despite existing rules to tackle delays in studying in the Netherlands, researchers can analyse the performance of Dutch students by distinguishing between slower and faster progress based on achieved credit points per semester (see e.g. Arnold and Straten 2012; Non and Tempelaar 2016). The situation in the Scandinavian countries (see e.g. Avdic and Gartell 2015) is quite similar to Germany where there is a great awareness of the problem of young people spending too much time in the education system (see e.g. Behr and Theune 2016). Surely, the situation is different in the Anglo-American countries with extraordinarily high tuition fees pressuring students to avoid delays in studying (see e.g. Blanden and Machin 2013). Since many economics of education researchers focus on these countries, this may explain the lack of research on study progress. Apart from a recent contribution from Bound, Lovenheim, and Turner (2012), most of the US-focused research on study delay discusses postgraduates (e.g. Stock and Siegfried 2006; Groen et al. 2008; Stock, Siegfried, and Aldrich Finegan 2011). Note that in the following we terminologically distinguish between undergraduates (bachelor), graduates (master) and postgraduate (Ph.D.) students in the present article, although the latter are of no further concern here.

${ }^{2}$ See e.g. Bound, Lovenheim, and Turner (2012) and Garibaldi et al. (2012). With respect to the country examined in this article, Germany, the KMK (Kultusministerkonferenz) comments on the implementation of the bachelor-master structure in a document from 12 June 2003 and lists shorter study time as the first expected result from these reforms in the introductory text.
} 
Nevertheless, it is primarily an empirical question whether a specific selection criterion predicts academic achievement and thus facilitates or frustrates the admission of successful students. To provide empirical evidence on the predictive power of any potential admission criterion, we require data. While previous research finds a significant relationship between undergraduate grades and graduate grades (see e.g. Kuncel, Credé, and Thomas 2007), there are two shortcomings with the available evidence. One is that study progress has not yet been established as an indicator of student performance. The second concerns the novel and thus unexamined environment in the European educational system after the implementation of the Bologna reforms. In this context, the problem of available evidence becomes even more striking as European lawmakers have already implemented a framework in which universities have to find their future graduate students among applicants with undergraduate degrees. As an important facet of the Bologna goals, the comparability of degrees across institutions of higher education constitutes an idea that resulted in the legal obligation to use UGPA as the primary admission criterion. This intervention in the decision process of universities restrains the newly given right to select but also the attempt to verify empirically that UGPA is a valid predictor of graduate performance. As long as universities adhere to the law, only applicants with higher UGPA are observable in real data from attractive graduate programmes, while individuals with lower UGPA are excluded from such programmes, which in turn leads to the exclusion of data that could falsify the proposition that UGPA is a primary predictor of future academic success. ${ }^{3}$

At this point, a fortunate coincidence from the perspective of research comes into play. In 2010, a renowned department of economics at one of the largest and most popular German universities was in the news for violating the law regarding the role of UGPA in the admission procedure. We use the availability of the data from this department to examine the predictive power of UGPA as an admission criterion. This approach gives a unique chance to address the question of how students with low
UGPA perform in a high-quality graduate programme to which, under existing legal circumstances, they could have never been admitted.

Our correlation results substantiate the theoretical predictions and thereby give credence to the objections against the legal practice of giving priority to UGPA. We can confirm the validity of the performance predictor UGPA only for one performance measure, graduate grade point average (GGPA). With respect to study progress, however, the predictive power is clearly lower. Discussing our concerns that prioritization of undergraduate grades may set incentives to encourage study delay even further, this article sheds light on a relevant problem in the European system of higher education.

The remainder of our article is structured as follows. In Section II, we build a simple model based on students' decisions and derive testable hypotheses from it. Section III discusses the legal framework and the background of the historic case that allows the empirical verification of the previously established hypotheses. Section IV presents the empirical results, which are then discussed in terms of their policy implications in Section $\mathrm{V}$ and is followed by the conclusion.

\section{Theoretical framework}

The purpose of our theoretical model is to show how students decide on study progress on the one hand, and on effort on the other. We use a stylized framework in which the number of exams completing by the student approximates study progress and effort is one of the main determinants of receiving a high average grade. Moreover, we consider only one time period, e.g. one semester, implicitly assuming that students' behaviour during this time period is representative for other time periods. As mentioned in the introduction, the main result of the model is that some students' trade-off study progress against higher average grades. Complicating the model, for instance by considering two or more periods, would not alter this result in a qualitatively way.

${ }^{3}$ Obviously, the legal intervention of enforcing UGPA as an admission criterion does not matter much to low quality programmes with small numbers of applicants. Instead, the discussion here takes place in a scenario with an attractive university, in which applications for the study programme broadly outnumber study places, so that the issue of how to select candidates and the legal basis for the selection have strong relevance. Moreover, admission tests constitute another option, which, however, in our setting, does not receive further consideration. 


\section{Set-up}

At the beginning of the semester, students make two decisions. They decide about the total number of exams $x$ which they will complete and they choose the level of learning effort $e$ per exam. Exams take place at the end of the semester. We assume that each student is endowed with an exogenously given ability level $a$, which reflects time-invariant individual-specific skills. ${ }^{4}$

The student's utility function is given by

$$
U=U_{L}(e, x, a)+\delta U_{G}(e, a),
$$

with $U_{L}$ and $U_{G}$ denoting the utility of learning during the semester and of receiving grades at the end of the semester, respectively. Note that the latter is weighted by the (exogenously given) parameter $\delta(>0)$. If $\delta$ is relatively high (low), students have a stronger (lower) incentive to provide higher (lower) efforts. This is similar to the interpretation by de Paola and Gioia (2017) who assume that $\delta$ reflects the students' level of patience. The more patient students are, the more important is receiving high average grades and vice versa.

During the semester, students provide a level of total effort ex, which is, however, associated with disutility ${ }^{5}$ captured by

$$
c=c(e x, a),
$$

We assume that the disutility function is increasing and convex in $e$ and $x$ (for a similar assumption, see de Fraja and Landeras 2006; or Liu and Neilson 2011). Intuitively, an increase in both the effort per exam and the number of exams raises total effort and thus disutility. We interpret $c_{e}$ and $c_{x}$ as the marginal disutility of effort per exam and of the number of exams, respectively, where the subscript characters denote partial derivatives. Cross derivatives are positive by assumption. A higher number of exams raises the marginal disutility of effort per exam and the respective interpretation holds for the impact of a higher $e$ on $c_{x}$. Moreover, students' ability levels also influence $c$. As argued by Bosshardt (2004), a student with a higher ability is more productive academically, so that, ceteris paribus, disutility decreases. We therefore assume $c_{a}<0$ and also $c_{e a}<0$ and $c_{x a}<0$.

Besides disutility, students receive a utility gain $u^{r}$ if they decide to complete exams. This captures the fact that students are confronted with a 'learning effect' due to the exams' preparation, independent of their final grades, which is beneficial in terms of utility. Furthermore, if students choose a positive number of $x$, they face a higher probability of conforming to the regular period of study which - by assumption - also has a positive utility effect. Accordingly, we assume that $u^{r}$ is an increasing function in $x$ :

$$
u^{r}=u^{r}(x), u_{x}^{r}>0, u_{x x}^{r}<0
$$

with $u_{x}^{r}$ being the marginal utility of $x$. Summing up, utility of learning during the semester is given by

$$
U_{L}(e, x, a)=-c(e x, a)+u^{r}(x) .
$$

At the end of the semester, students hear about the results of their exams. Three situations can be distinguished: (i) students pass the exam with a high grade and receive an exogenously given utility gain of $u^{+}$; (ii) students pass the exam, but receive only a low grade associated with a utility gain of $u^{-}$; and (iii) students fail and receive $u^{f}$ utility units $\left(u^{+}>u^{-}>u^{f}\right)$. To simplify notation, we normalize $u^{-}$at 1 and $u^{f}$ at 0 , without loss of generality.

The probability of passing the exams which the student has completed is denoted by $p$, while the probability of gaining a high average grade is denoted by $q .{ }^{6}$ We assume that both probabilities positively depend on the learning effort per exam and the student's ability level, where the functions are concave in both arguments (see Van der Klaauw and van Vuuren 2010 for analogue assumptions):

$$
\begin{aligned}
& p=p(e, a)(0 \leq p \leq 1), \\
& q=q(e, a)(0 \leq q \leq 1) .
\end{aligned}
$$

Hence, we can describe the student's utility of gaining a certain average grade as

${ }^{4}$ Notably, students have perfect knowledge about their abilities in our framework. See Gary-Bobo and Trannoy (2008) for a study that relaxes this assumption.

${ }^{5}$ Disutility captures the opportunity costs of time spent on studying.

${ }^{6}$ To hold our model as simple as possible, we assume that the probabilities $p$ and $q$ are independent of each other. Note also that we consider the average grade of the exams $x$ and we disregard the fact that $p$ and $q$ might decline in $x$ because this would not alter our results, but complicate the model. 


$$
\begin{aligned}
U_{G}(e, a)= & p(e, a) q(e, a) u^{+} \\
& +p(e, a)(1-q(e, a)) .
\end{aligned}
$$

\section{Optimization}

Inserting (4) and (7) into (1) yields

$$
\begin{aligned}
U(e, x, a, \delta)= & \delta\left[p(e, a) q(e, a) u^{+}+p(e, a)\right. \\
& (1-q(e, a))]-c(e \cdot x, a)+u^{r}(x) .
\end{aligned}
$$

Students choose the level of effort per exam $e$ and the total number of exams $x$ to maximize (8). The first-order conditions of that problem are given by gaining a higher average grade (see Appendix for the proof).

Looking at two students with identical levels of $\delta$ but different abilities, we can show that $U_{e a}>0$ holds [see (11) and Appendix], which indicates that high-ability students have an incentive to provide higher efforts. Moreover, marginal utility of competing exams increases, i.e. $U_{x a}>0$, such that highability students have an incentive to increase $x$ [see (10)]. These direct effects are mitigated or even compensated by the fact that $e$ and $x$ are substitutes in our model, i.e. $U_{e x}<0$. If, for example, highability students raise $e$, and the implied reduction of $x$ is high enough to outweigh the initial incentive

$$
U_{e}=\delta\left[\begin{array}{l}
\left(p_{e}(e, a) q(e, a)+p(e, a) q_{e}(e, a)\right) u^{+}+p_{e}(e, a)(1-q(e, a)) \\
-p(e, a) q_{e}(e, a)
\end{array}\right]-c_{e}(e x, a)=0,
$$

$$
U_{x}=u_{x}^{r}(x)-c_{x}(e x, a)=0 .
$$

Rearranging (9) yields

$$
\begin{gathered}
\delta\left[\left(u^{+}-1\right) p_{e}(e, a) q(e, a)+\left(u^{+}-1\right) p(e, a)\right. \\
\left.q_{e}(e, a)+p_{e}(e, a)\right]=c_{e}(e x, a) .
\end{gathered}
$$

The left-hand side can be interpreted as the marginal utility gain of $e$, while the right-hand side captures the marginal disutility (or marginal costs in terms of utility) of $e$. Analogously, we obtain from (10) $u_{x}^{r}(x)=c_{x}(e x, a)$. As a result, students choose $e$ and $x$ so that the associated marginal disutilities (or marginal costs) are equalized through the associated marginal utility gains.

\section{Hypotheses}

Consider two students with identical abilities but different levels of $\delta$, where we interpret $\delta$ as the students' level of patience. As shown by (11), marginal utility gain of effort is higher for the patient student, which raises effort. As disutility of $x$ increases in $e$, the patient student chooses a lower number of exams [see (10)]. Patient students thus substitute $x$ against $e$, which implies that they tradeoff study progress against a higher probability of to increase $x$, we again would observe a trade-off between study progress and higher average grades (see Appendix for the proof).

Consider a top university that uses UGPA as the admission criterion to select students for graduate (master) programmes who should be leading in terms of their average grades in the master programme and in terms of their study progress. The UGPA criterion implies that the university selects those students with high effort levels $e$ and/or students with high ability levels $a$. It is reasonable to assume that these students would perform well in the master programme in terms of grade, but as discussed before, it is less clear whether these students would also perform well in terms of study progress. This ends up in two hypotheses:

H1: The predictive power of UGPA is relatively strong for the performance measure GGPA.

H2: The predictive power of UGPA is relatively weak for the performance measure graduate study progress.

Further aspects can affect the predictive power of UGPA, which are not explicitly included in our model. For instance, identical UGPA achieved at different institutions may reflect different levels of

\footnotetext{
${ }^{7}$ For the second-order conditions of the utility maximum, we can use (10) and the assumption $c_{e x}=c_{x e}>0$ to obtain: $U_{x x}=U_{x x}^{\prime}-c_{x x}<0$ and $U_{e x}=U_{x e}=-c_{e x}<0$. To ensure a maximum, we assume in addition that $U_{e e}<0$ and $|H|=U_{e e} U_{x x}-U_{e x} U_{x e}>0$ hold, with $|H|$ denoting the determinant of the Hesse-Matrix.
} 
student qualification, ${ }^{8}$ so that the educational outcomes are affected by the quality of the previously attended school. Hence, by considering additional information on the undergraduate programme, the predictor UGPA may become more precise. ${ }^{9}$ This leads to our third hypothesis:

\section{H3: The predictive power of UGPA becomes stronger} by considering differences in undergraduate study factors, such as school quality.

In practice, admission committees require an applicant to provide more information, such as the high school grade point average (HGPA). On the one hand, this HGPA obviously differs from the other one due to a larger time-lag. On the other hand, the above trade-off between grades and study progress is certainly of less relevance at high schools. This implies that students with a high HGPA signal that they can receive high grades even if they have no opportunity to reduce the number of exams per period. These considerations lead to a fourth and final hypothesis:

H4: The predictive power of HGPA is relatively strong for the performance measure graduate study progress.

With respect to the policy discussion, it is noteworthy to point out that some of the potential admission criteria are not necessarily allowed to be used in the current European system of higher education, such as a differentiation between schools and their potential differences in institutional quality. The fact that even the use of HGPA in graduate admission procedures is currently an open question for the courts leads to the legal background of our discussion.

\section{Legal background}

\section{Student selection after the Bologna reforms}

In order to understand why universities may be forced by lawmakers to give substantial consideration to UGPA in their selection of graduate students, it is essential to know about the current legal framework in the European system of higher education. In fact, the illegality of ignoring undergraduate grades in the admission procedure relates directly to one of the key ideas of the Bologna concept. Following the Bologna Declaration of 1999, many European countries have, over the past few years, implemented systematic changes in their educational systems. As one of the most severe consequences for Germany, previous diploma degrees have been replaced with two separate and consecutive degrees, divided into 3-year undergraduate (bachelor) and 2-year graduate (master) study programmes. The introduction of the latter has led to a new situation regarding how universities select and thereby compete for qualified students. Instead of a centralized public institution, the faculties are responsible for the student selection, which conforms to the notion of independent and autonomous universities. ${ }^{10}$

However, the legal reality has shown that another key element of the Bologna concept unmistakably limits the autonomy in admission decisions: the implementation of a system of 'comparable degrees' all over Europe (Bologna Declaration 1999). While the intention was to maintain 'full respect of [...] University autonomy' in the process of consolidation, the aspect of competition between universities is mentioned not once, and only the competitiveness of the entire European education system receives attention. Obviously, there is a conflict between more comparable degrees and the idea of having institutional diversity within the area of higher education. $^{11}$

In recent years, the countries that signed the Bologna declaration have implemented the concept into national law. In particular, the legal framework in which universities had to select their students has been reformed markedly and now contains new regulations in line with the Bologna objectives. In the concrete situation of Germany, we have to consider the situation on the state level, as federalism is a

${ }^{8}$ Note that 'qualification' means education qualification that an individual can affect through studying.

${ }^{9}$ The same argument relates to the actual contents studied in the undergraduate programme, which gives occasion to distinguish between courses of study. The idea is that one student with worse grades but with more relevant study contents may actually be better qualified than someone with better grades but from a completely different area of study. Apart from the undergraduate study programme itself, students may differ in how much effort they put into alternatives to actual studying (e.g. internships, semester abroad, working), which might positively affect qualification levels but negatively affect grade outcomes.

${ }^{10}$ Arguably, this aspect of the reforms appears as more accentuated in the Bologna declaration's predecessor, the Bologna Magna Charta Universitatum of

1988.

"Interestingly, a follow-up document published one year after the declaration seems to express a need for clarification: The Bologna process aims at creating convergence and, thus, is not a path towards the "standardisation" or "uniformisation" of European higher education' (Confederation of EU Rectors' Conference and Association of European Universities 2000). 
noticeable characteristic of the German education system. The main statutory basis for the implementation of admission procedures in Germany is a treaty, produced by representatives from all the state governments and thus applicable to all German states per ratification. ${ }^{12}$ The treaty's Article 10 (1) S.1 No. 3 contains a list of different criteria for the allocation of available study places, which involves diverse aspects, such as the type of vocational training. While the treaty generally does not require the institutions of higher education to consider all the listed criteria, Article 10 (1) S.2 makes clear that there is one significant exception. Accordingly, the first criterion in the list, which is the level of qualification, must have a significant influence on the selection decision. To further illustrate what this means, the treaty refers to state law. In the case of Germany's most populous state, North Rhine-Westphalia (NRW), lawmakers have concretized the legal framework for institutions of higher education in a separate law on student admission (Hochschulzulassungsgesetz). According to its $\S 4$ (6), the final examination certification of the first professionally qualifying degree takes the place of the level of qualification, in reference to the above treaty. This passage not only forces universities to consider UGPA as the primary admission criterion; it is in line with both the jurisdiction in other German states and the Bologna idea of comparability between degrees and thus institutions. ${ }^{13}$

\section{The case of an illegal admission procedure}

In 2010, the admission procedure of a renowned German university became a public issue, triggering a debate on graduate student selection, as some undergraduate alumni successfully sued the department of economics which had previously dismissed their applications. ${ }^{14}$ According to court rule (file reference: 9 L 529/10) of 15 November 2010, the admission committee gave insufficient significance to the outcomes of undergraduate studies when selecting graduate students. Without any media coverage, and thus unknown to the public, were the antecedents to this case. While the 2010 procedure that was declared illegal by the court nevertheless included UGPA as a minor criterion, the official document on which the student selection was based dated back to the introduction of the master programmes in 2008 and was free of any admission criteria related to undergraduate studies. ${ }^{15}$

The idea behind this was to allow for student selection without any consideration of UGPA and to use other information about the candidates from their applications. The calculation of scores on the basis of a diverse set of criteria, such as the motivation expressed in a separate letter, seemed preferable to many at the faculty in order to get the most promising students. Due to increasing awareness of the actual legal circumstances, all decisions on applications to the business and economics programmes considered UGPA in one way or another in 2010, although still not significantly enough according to court rule.

The prime reason of the faculty's reluctance to use UGPA as a criterion in the selection of students was a great deal of scepticism towards the notion of comparable grades across institutions. Especially with regard to the different school types in Germany (e.g. academies, colleges), there were strong doubts that bachelor alumni were similarly qualified when they got the same UGPA but had received their degrees from different institutions. In consequence, even in the 2010 procedure that was rejected by the courts, there is evidence for such distrust in the comparability of degrees. ${ }^{16}$

\footnotetext{
${ }^{12}$ This treaty (Staatsvertrag über die Errichtung einer gemeinsamen Einrichtung für Hochschulzulassung) dates from 5 June 2008 and was negotiated and ratified by all German states.

${ }^{13}$ For the idea of standardization between school types, the German law offers several recent examples. For instance, NRW lawmakers consider degrees from academies as equal to those from universities ( $\$ 49$ (7) S.3, Hochschulgesetz NRW). The German Federal Constitutional Court even referred to the Bologna process in a court rule of 2010, when discussing the convergence of universities and colleges that lawmakers have fostered in recent years. This court rule from 13 April 2010 can be found on the court's webpage under the code BvR 216/17. Note that there are three major German institutions of higher education, which are the university, the academy (Berufsakademie) and the college (Fachhochschule). University of applied sciences is an alternative term for the latter, but we abstain from using this name for the sake of clarity. Also note that the term school refers to all these three institutions, in contrast to the high school that students attended before entering higher education.

${ }^{14}$ In November of that year, several national newspapers in Germany reported on the case, such as Tagesspiegel, Hamburger Abendblatt and Tageszeitung. Further coverage can be found on the internet. For instance, there are reports by major online news sites, such as Welt Online from 23 November 2010 . On 21 January 2011, the online portal of the Frankfurter Rundschau wrote about German universities' fear of losing autonomy in their student selection as a consequence of the courts' decisions and the need to give UGPA a determining influence.

${ }^{15}$ The relevant document (Zugangs- und Zulassungsordnung) is routinely published as part of the proclamations (Amtliche Bekanntmachungen) and made publicly available on the university webpage.

${ }^{16}$ The procedure included UGPA as a criterion but used institutional weights for each school, allowing for differentiation of UGPA according to their origin. The judge expressed serious concerns about this, while referring to the goals of the Bologna process that are likely to be affected by such a differentiation between institutions of higher education.
} 
Nevertheless, this 2010 cohort of graduate students does not provide suitable data for investigating UGPA as an admission criterion since its consideration in the student selection led to implicit thresholds at the bottom of the grade scale. This is the so-called range restriction problem outlined in the literature on performance predictors (Kuncel, Hezlett, and Ones 2001). Furthermore, there was also a reaction among the potential applicants as students increasingly realized the importance of the UGPA. Contrariwise, this was actually not clear to the undergraduate students beforehand. Considering that in 2008 the department's first master students started as part of a very small precohort that was insignificant in numbers, those students who applied in the time between 2008 and the first court rulings provide the best possible data for our research objective of testing the validity of UGPA as a performance predictor. The reluctance to consider UGPA in the selection of students allows a unique chance to see how well the predictive power of this admission criterion in a real scenario may actually be. Under regular circumstances, implicit or explicit grade thresholds frustrate such a correlation analysis, at least in the case of a high quality, and thus popular, university. Only in the case of legal disobedience do we have the chance to investigate how those students who are routinely excluded by law perform.

\section{Empirical analysis}

\section{Data}

We have data on all 210 graduate students who began studying business administration or economics in our 1-year period of investigation, which includes the winter semester of 2009/2010 and the summer semester of $2010 .{ }^{17}$ As can be read in court rulings and press articles, there were significantly more than 1000 applicants for business administration alone in 2010. While overall numbers were somewhat smaller before in our year of interest, it was still a four-figure number of applicants of whom several hundred gained admission. These individuals provide us with a data set that is free of any missing data problem and is comparatively large for predictor research, especially where the analysis of graduate students' performance is concerned (Kuncel, Credé, and Thomas 2007, 57).

A key aspect in our article is the consideration of study progress as a second success dimension. Just like elsewhere in Europe (see e.g. Leuven, Oosterbeek, and van der Klaauw 2010, 1247), this factor has utmost importance for the programme organizers, also because faculty funding partially depends on it. Thus, the faculty is inclined to give students in all subject areas a fair chance to pass exams in the required time. The above-described possible trade-off between grade achievement and study speed is present and well-known among students and faculty members. Accordingly, some students have an incentive to delay exams into the next semester. Just like at other universities, little can be done to prevent or sanction such strategic behaviour, even if students are engaged in it only to improve their grade prospects.

For all graduate students, we have data from the original application documents, which contain previous grades and other information. We benefit from the fact that applicants were required to substantiate everything via documents. Thus, we can safely assume correctness of the application data obtained since manipulation is reason enough to deny a study place. We add administrative information about exams from the period of investigation in order to establish the two measures of performance. Hence, our data set is also free of any overstatement issues known from surveys. ${ }^{18}$ Considering the challenges surrounding the collection of student data (see e.g. Machin and Puhani 2005), we argue that we have a very accurate picture of each student before and after admission.

Our first graduate performance measure, GGPA, is the weighted grade points average for each student, which considers differences in the number of credit points per exam. For the second success dimension, study progress, we use achieved CP per semester at the outset of the programme, which was also the key measure used by the faculty for evaluating the success

\footnotetext{
${ }^{17}$ In Germany, the winter semester officially starts on October 1 and ends on March 31, while the summer semester starts on April 1 and ends on September 30. In order to apply for study programmes starting in winter, applications are allowed until July, which is the month in which most applicants submit their documents. All selection decisions are made in August, so that applicants have enough time to enrol for the winter semester.

${ }^{18}$ Beekhoven, de Jong, and van Hout (2003) point out the advantages of the reliable administrative data in comparison with surveys that have a bias towards more successful students who are more willing to reply to questionnaires.
} 
of the student selection. In line with conclusions drawn by other researchers, we consider final completion time as a problematic measure as it not only expresses performance but also 'events beyond the control of the student' (Kuncel, Hezlett, and Ones 2001). Students may recognize worse job prospects at the end of their studies or extraordinary opportunities in the form of internships or studies abroad may emerge and hence prolong study time. ${ }^{19}$ Yet, in the first period of the study programme, achieving less than the standard $30 \mathrm{CP}$ in a semester is a definite problem for both faculty and student, and clearly expresses underperformance.

Descriptive information on the student data is given in the Appendix (see Table A1). Figure 1 shows a graphical illustration of the key variable of interest, the UGPA, and compares it with the GGPA as one of the two success measures. Both grade point averages are distributed quite similarly and testing for normality underlines the properties of our data even further as the null hypothesis of normal distribution cannot be rejected at conventional levels. There is no range restriction problem that one would necessarily expect in such a context. Regarding the second success measure of study progress, we observe that some students collected more $\mathrm{CP}$ than the required 30 , which suggests that the workload in this graduate programme was quite manageable.

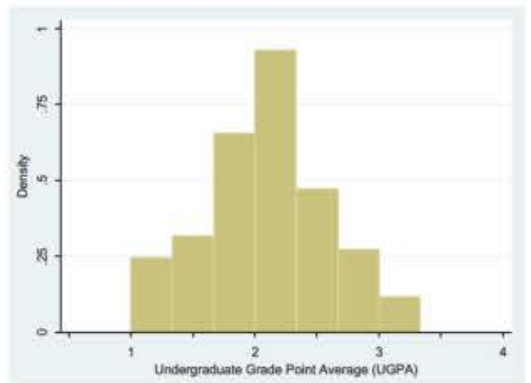

\section{Empirical outline}

The evaluation of predictors of student performance and thus potential admission criteria looks descriptively at whether students with certain observable attributes perform better or not. Hence, when policy papers discuss admissions (e.g. German Council of Science and Humanities 2004, Helms 2008), cited studies are correlation analyses, and so are the investigations included in meta-analyses on predictor validity (e.g. Kuncel, Hezlett, and Ones 2001; Kuncel, Credé, and Thomas 2007). Performance indicators like previous grades thereby appear as proxies for hard to observe determinants like ability or time preference, which reflects the idea of making selection decisions on the basis of simple but legal criteria. In our analysis, just like a hypothetical admission committee, we wish to know whether UGPA is a good proxy for applicants' potential to perform well in the master programme. Despite the availability and the potentially significant role of socio-demographic factors in academic performance, we do not use this available information, because, firstly, our research objectives require us to inspect empirical relationships between predictors and performance and not to isolate causal determinants of the latter. Secondly, these factors should play no role in the admission choices from a legal perspective. Still, multiple regression models are needed here to

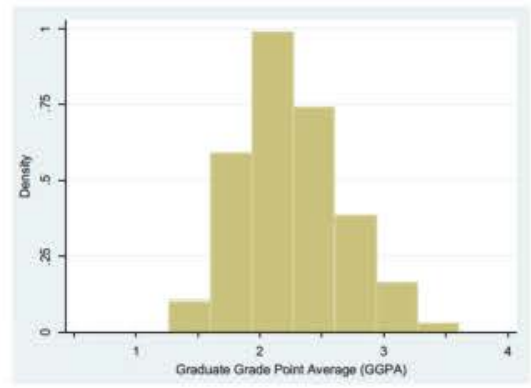

Figure 1. Distribution of grade point averages.

Notes: Germany's grade system goes from 1.0 to 4.0 , the latter of which typically constitutes the worst possible grade in order to still pass exams. The left-hand illustration is based on the entire sample of 210 graduate students. The right-hand illustration excludes seven graduate students who achieved no CP at all.

\footnotetext{
${ }^{19}$ The concrete background of our case gives further reason to not use performance data from beyond the first two semesters as a variety of factors that are not in the hands of the students influence how taking semesters abroad (which mostly happens after the first year) affect final completion time. Some outside courses are more easily taken account of than others, administrators differ in their willingness to support course accounting and even factors like the social security situation of a student can influence decisions concerning semesters abroad. For internships, the situation is similarly complex. In contrast, students are less likely to engage in such non-curricular activities in the first two semesters, in which they focus on passing the required courses on site, and only a small group of students took a semester off (for e.g. internships). Note that to ensure comparability, we took the credit points from the few students who did exams in only one semester during the first year, and we divided the number of CP for all other students by two.
} 
more deeply investigate the potential correlations as other factors may affect the link between graduate student performance and its predictors.

In fact, how well determinants predict academic performance can be affected by differences in exam standards, as lecturers can be more or less generous in giving good grades to their students. To tackle this issue, researchers either use 'deflators' to consider differences in standards (Butler, Aldrich Finegan, and Siegfried 1994, 208) or they add further variables (e.g. Borg and Stranahan 2002; Win and Miller 2005). Such consideration of potential performance measurement problems could however lead to a problem when additional subject variables capture variation in actual performance. We exploit the fact that programme structures are well-incorporated across majors, so that major students are allowed to choose courses from other majors as part of their minor programme. This implies an overlap of different major students for one and the same programme offer and allows us to use control variables for study content instead of major only, arguing that a performance-dependent selection of students into study contents is less likely than a selection into majors.

\section{Main results}

The main question addressed in the empirical analysis concerns the predictive power of UGPA for graduate student performance. As can be observed from the correlation matrix in Table 1, which only includes data from students who passed at least one exam, there is a very strong positive relationship between UGPA and GGPA. Better grades in undergraduate programmes go along with better grades in the graduate programme, confirming our first hypothesis. The main insight of our study concerns the other relationship, which refers to the predictive
Table 1. Correlation matrix.

\begin{tabular}{|c|c|c|c|c|c|}
\hline & GGPA & GCP & UGPA & UCT & HGPA \\
\hline \multicolumn{6}{|l|}{ Performance outcomes } \\
\hline $\begin{array}{l}\text { Graduate grade point averages } \\
\text { (GGPA) }\end{array}$ & 1 & & & & \\
\hline $\begin{array}{l}\text { Graduate credit points (GCP) } \\
\text { Performance predictors }\end{array}$ & $0.22^{*}$ & 1 & & & \\
\hline $\begin{array}{l}\text { Undergraduate grade point average } \\
\text { (UGPA) }\end{array}$ & $0.28^{*}$ & 0.06 & 1 & & \\
\hline $\begin{array}{l}\text { Undergraduate completion time } \\
\text { (UCT) }\end{array}$ & 0.09 & $0.17^{*}$ & $0.31^{*}$ & 1 & \\
\hline $\begin{array}{l}\text { High school grade point average } \\
\text { (HGPA) }\end{array}$ & $0.28^{*}$ & $0.18^{*}$ & $0.37^{*}$ & $0.23^{*}$ & 1 \\
\hline
\end{tabular}
(HGPA)

Notes: Correlations are based on the smaller sample of 203 master students, which excludes seven students who achieved no CP from the 210 total. Level of statistical significance is ${ }^{*} p<0.05$.

power of UGPA for graduate study progress. As predicted by our second hypothesis, this link is rather weak, which becomes very obvious in comparison with the other outcome. Hence, applicants with bad undergraduate grades are not necessarily bad performers in graduate programmes when the achievement of CP is considered. In fact, passing exams as the key outcome for programme organizers is only weakly predicted by UGPA.

To confirm the role of UGPA as revealed in the correlations, we address the potential problem of performance measurement error by using different empirical methods and varying definitions of the dependent variables. We apply both OLS regressions and additional probability estimations, for which we consider (five) ordinal success categories for each of the dimensions, grades and progress. $^{20}$

Panel (a) in Table 2 presents the regression results for the performance measure GGPA, whereas the results in the lower panel (b) are based on the same specifications for the second performance dimension of collected CP per semester. We also include content indicators to consider the potential role of basic differences between the subjects. We find only little evidence for subject diversity in regard to grades, while there is some variation in regard to study progress.

\footnotetext{
${ }^{20}$ The use of the ordered probit method helps when dealing with students who have no grades at all. Because of dropping out or simple failure in the attempt to pass any exam, some graduate students have an outcome of $0 \mathrm{CP}$ and thus no grade (average) at all. One simple solution is to exclude those observations; yet, in reference to the literature that considers dropouts as a special form of failure (e.g. Stinebrickner and Stinebrickner 2008a), we present outcomes for the entire data and for the sample without the graduate students who passed no master exam at all. In order not to exclude them from analyses of the full data set, we assign to them the worst possible grade, which underlines why the additional use of a method that considers ordinality of the dependent variable appears to be helpful here. Arguably, one could regard not passing any exam as an endogenous decision. We thus present results for both samples.
} 
Table 2. Undergraduate grades and graduate student performance.

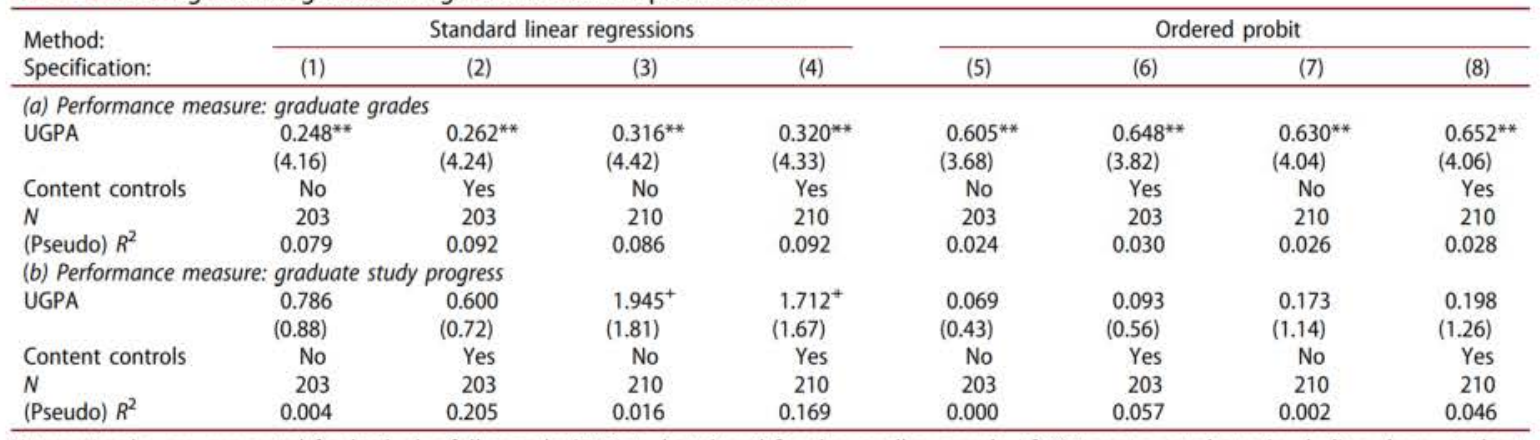

Notes: Results are presented for both the full sample (210 students) and for the smaller sample of 203 master students (excluding those students who achieved no credit points at all). The dependent variable in the regressions of panel (a) is the graduate grade point averages (GGPA) respectively in the regressions of panel (b) the achieved credit points (per semester) in the graduate programme. For the ordered probit analysis, the performance measures are split into quartiles to have four (respectively five) categories (if the seven students without CP are included as a separate category). For illustration purposes, all grade measures are multiplied by minus one. Content controls are variables reflecting the amount of courses in a major subject. SEs are in parentheses. Levels of statistical significance are $+p<0.1,{ }^{* *} p<0.01$.

In further analyses, we apply alternative approaches to consider subject diversity by means of major and course variables (results available upon request). We can conclude that the main findings are robust regarding the issue of exam standards. Whether we include subject variables or not, whether consideration takes place in one way or another, the predictive power of UGPA remains strong for the performance measure GGPA but only weak for the second performance measure, study progress. As predicted by our model, some undergraduate students prefer to put in high effort, and thus have on average a higher grade success, but also choose a slower study progress. Contrariwise, there are students who, instead of grades, focus on finishing their studies quickly. Since these students have the qualifications required to pass the exams in a high-quality course of study, which is actually what the faculty is looking for, UGPA is not a fully accurate indicator of later performance.

\section{Additional results}

As our third hypothesis suggests that the predictive power of UGPA may be affected by aspects related to the prior undergraduate programmes, we consider the undergraduate institution and the previous study programme in the following. To analyse the role of institutional diversity in undergraduate degrees, we include first a parsimonious and then an extended set of variables in our specifications. The former only differentiates between the overall type of institution (university, college or academy) and whether the student received an undergraduate degree from abroad. The broader model contains a variable for every institution with at least four observations in our data.

The results in Table 3 show that the previously attended school itself does play a role but not so much previous school type. Undergraduate alumni from some universities are indeed less successful, which we observe for both success dimensions. However, apparent increases in the validity of UGPA as a predictor of graduate performance, confirming our third hypothesis, can hardly be detected. Another finding relates to students who did not switch schools. Study progress of such stayers is not significantly better but they do get higher grades on average. Less successful in both respects are students from abroad. Rather weak differences emerge between the three institutions of higher education, which, despite obvious selectivity, is a noteworthy observation concerning the motives behind the admission policies at the faculty. In further analyses, we check whether differences in what graduate students actually studied before matter in the context of how well UGPA can explain later success (see Appendix Table A2). While there seems no general effect from what students learned during their time as undergraduates, the fit between undergraduate and graduate contents turns out to be relevant for GGPA, implying that those who 
Table 3. Undergraduate grades, previous school and graduate student performance.

\begin{tabular}{|c|c|c|c|c|c|c|c|c|}
\hline \multirow{2}{*}{$\begin{array}{l}\text { Method: } \\
\text { Specification: }\end{array}$} & \multicolumn{4}{|c|}{ Standard linear regressions } & \multicolumn{4}{|c|}{ Ordered probit } \\
\hline & (1) & (2) & (3) & (4) & (5) & (6) & (7) & (8) \\
\hline \multicolumn{9}{|c|}{ (a) Performance measure: graduate grades } \\
\hline UGPA & $\begin{array}{l}0.334^{* *} \\
(5.14)\end{array}$ & $\begin{array}{l}0.425^{* *} \\
(6.51)\end{array}$ & $\begin{array}{l}0.388^{* *} \\
(5.01)\end{array}$ & $\begin{array}{l}0.491^{* *} \\
(6.18)\end{array}$ & $\begin{array}{l}0.793^{* *} \\
(4.20)\end{array}$ & $\begin{array}{l}1.200^{* *} \\
(5.70)\end{array}$ & $\begin{array}{l}0.768^{* *} \\
(4.37)\end{array}$ & $\begin{array}{l}1.169^{* * *} \\
(5.95)\end{array}$ \\
\hline \multicolumn{9}{|l|}{ Previous school } \\
\hline College & $\begin{array}{l}-0.216^{*} \\
(-2.03)\end{array}$ & $\begin{array}{l}-0.262^{*} \\
(-2.02)\end{array}$ & $\begin{array}{l}-0.195 \\
(-1.48)\end{array}$ & $\begin{array}{l}-0.248 \\
(-1.51)\end{array}$ & $\begin{array}{l}-0.472 \\
(-1.56)\end{array}$ & $\begin{array}{l}-0.568 \\
(-1.45)\end{array}$ & $\begin{array}{l}-0.363 \\
(-1.24)\end{array}$ & $\begin{array}{l}-0.461 \\
(-1.21)\end{array}$ \\
\hline School abroad & $\begin{array}{l}-0.503^{* *} \\
(-4.05)\end{array}$ & $\begin{array}{l}-0.488^{* *} \\
(-3.77)\end{array}$ & $\begin{array}{l}-0.551^{* *} \\
(-3.75)\end{array}$ & $\begin{array}{l}-0.525^{* *} \\
(-3.33)\end{array}$ & $\begin{array}{l}-1.144^{* *} \\
(-3.04)\end{array}$ & $\begin{array}{l}-1.003^{*} \\
(-2.44)\end{array}$ & $\begin{array}{l}-1.004^{* *} \\
(-3.03)\end{array}$ & $\begin{array}{l}-0.859^{*} \\
(-2.32)\end{array}$ \\
\hline Same university & & $\begin{array}{l}0.170^{*} \\
(2.16)\end{array}$ & & $\begin{array}{l}0.193^{+} \\
(1.97)\end{array}$ & & $\begin{array}{l}0.760^{* *} \\
(3.23)\end{array}$ & & $\begin{array}{l}0.737^{* * *} \\
(3.23)\end{array}$ \\
\hline School dummies & No & Yes & No & Yes & No & Yes & No & Yes \\
\hline$N$ & 203 & 203 & 210 & 210 & 203 & 203 & 210 & 210 \\
\hline (Pseudo) $R^{2}$ & 0.161 & 0.302 & 0.151 & 0.263 & 0.046 & 0.113 & 0.045 & 0.101 \\
\hline College & $\begin{array}{l}0.131 \\
(0.08)\end{array}$ & $\begin{array}{l}-0.242 \\
(-0.12)\end{array}$ & $\begin{array}{l}0.198 \\
(0.10)\end{array}$ & $\begin{array}{l}-0.143 \\
(-0.06)\end{array}$ & $\begin{array}{l}0.024 \\
(0.08)\end{array}$ & $\begin{array}{r}0.078 \\
(0.20)\end{array}$ & $\begin{array}{r}0.029 \\
(0.10)\end{array}$ & $\begin{array}{r}0.086 \\
(0.23)\end{array}$ \\
\hline Academy & $\begin{array}{c}2.288 \\
(0.74)\end{array}$ & $\begin{array}{r}0.239 \\
(0.08)\end{array}$ & $\begin{array}{c}2.475 \\
(0.64)\end{array}$ & $\begin{array}{r}0.561 \\
(0.15)\end{array}$ & $\begin{array}{l}0.430 \\
(0.80)\end{array}$ & $\begin{array}{c}0.114 \\
(0.20)\end{array}$ & $\begin{array}{c}0.404 \\
(0.75)\end{array}$ & $\begin{array}{c}0.132 \\
(0.23)\end{array}$ \\
\hline School abroad & $\begin{array}{l}-3.342^{+} \\
(-1.74)\end{array}$ & $\begin{array}{l}-5.431^{* *} \\
(-2.72)\end{array}$ & $\begin{array}{l}-4.691^{*} \\
(-2.07)\end{array}$ & $\begin{array}{l}-6.605^{* *} \\
(-2.69)\end{array}$ & $\begin{array}{l}-0.251 \\
(-0.72)\end{array}$ & $\begin{array}{l}-0.627 \\
(-1.63)\end{array}$ & $\begin{array}{l}-0.363 \\
(-1.13)\end{array}$ & $\begin{array}{l}-0.704^{+} \\
(-1.94)\end{array}$ \\
\hline Same university & & $\begin{array}{l}-2.076^{+} \\
(-1.71)\end{array}$ & & $\begin{array}{l}-1.528 \\
(-1.00)\end{array}$ & & $\begin{array}{l}-0.398^{+} \\
(-1.73)\end{array}$ & & $\begin{array}{l}-0.299 \\
(-1.34)\end{array}$ \\
\hline School dummies & No & Yes & No & Yes & No & Yes & No & Yes \\
\hline$N$ & 203 & 203 & 210 & 210 & 203 & 203 & 210 & 210 \\
\hline (Pseudo) $R^{2}$ & 0.023 & 0.191 & 0.039 & 0.149 & 0.003 & 0.066 & 0.006 & 0.046 \\
\hline
\end{tabular}

Notes: See Table 2. School dummies reflect all universities and colleges, for which there are at least four observations. Levels of statistical significance are ${ }^{+}$ $p<0.1,{ }^{*} p<0.05,{ }^{* *} p<0.01$.

studied a different undergraduate programme before perform lower with respect to graduate grades. ${ }^{21}$

Finally, while there is a lack of empirical support for the third hypothesis, we focus in the following on our fourth hypothesis and empirically investigate the predictive power of HGPA. Replicating Table 2 with this alternative factor, Table A3 in the Appendix shows how HGPA predicts both kinds of performance remarkably well. In Table 4 , we provide a comparison between HGPA and our variable of

Table 4. Undergraduate grades, high school grades and graduate student performance.

\begin{tabular}{|c|c|c|c|c|c|c|c|c|}
\hline \multirow{2}{*}{$\begin{array}{l}\text { Method: } \\
\text { Specification: }\end{array}$} & \multicolumn{4}{|c|}{ Standard linear regressions } & \multicolumn{4}{|c|}{ Ordered probit } \\
\hline & (1) & (2) & (3) & (4) & (5) & (6) & (7) & (8) \\
\hline \multicolumn{9}{|c|}{ (a) Performance measure: graduate grades } \\
\hline UGPA & $\begin{array}{l}0.184^{* *} \\
(2.91)\end{array}$ & $\begin{array}{l}0.197^{* *} \\
(3.05)\end{array}$ & $\begin{array}{l}0.239^{* * *} \\
(3.21)\end{array}$ & $\begin{array}{l}0.247^{* *} \\
(3.24)\end{array}$ & $\begin{array}{l}0.472^{* *} \\
(2.69)\end{array}$ & $\begin{array}{l}0.512^{* *} \\
(2.85)\end{array}$ & $\begin{array}{l}0.498^{* *} \\
(3.02)\end{array}$ & $\begin{array}{l}0.523^{* * *} \\
(3.11)\end{array}$ \\
\hline HGPA & $\begin{array}{l}0.174^{* *} \\
(2.79)\end{array}$ & $\begin{array}{l}0.186^{* *} \\
(2.96)\end{array}$ & $\begin{array}{l}0.222^{* *} \\
(3.05)\end{array}$ & $\begin{array}{l}0.226^{* *} \\
(3.04)\end{array}$ & $\begin{array}{l}0.384^{*} \\
(2.20)\end{array}$ & $\begin{array}{l}0.414^{*} \\
(2.35)\end{array}$ & $\begin{array}{l}0.423^{* *} \\
(2.62)\end{array}$ & $\begin{array}{l}0.447^{* *} \\
(2.73)\end{array}$ \\
\hline Content controls & No & Yes & No & Yes & No & Yes & No & Yes \\
\hline \multicolumn{9}{|c|}{ (b) Performance measure: graduate study progress } \\
\hline UGPA & $\begin{array}{l}-0.074 \\
(-0.08)\end{array}$ & $\begin{array}{l}-0.176 \\
(-0.20)\end{array}$ & $\begin{array}{l}0.913 \\
(0.81)\end{array}$ & $\begin{array}{l}0.911 \\
(0.85)\end{array}$ & $\begin{array}{l}-0.087 \\
(-0.51)\end{array}$ & $\begin{array}{l}-0.078 \\
(-0.44)\end{array}$ & $\begin{array}{l}0.026 \\
(0.16)\end{array}$ & $\begin{array}{l}0.057 \\
(0.35)\end{array}$ \\
\hline HGPA & $\begin{array}{l}2.315^{*} \\
(2.49)\end{array}$ & $\begin{array}{l}2.211^{* *} \\
(2.61)\end{array}$ & $\begin{array}{l}2.980^{* * *} \\
(2.71)\end{array}$ & $\begin{array}{l}2.482^{*} \\
(2.39)\end{array}$ & $\begin{array}{l}0.426^{*} \\
(2.50)\end{array}$ & $\begin{array}{l}0.501^{* *} \\
(2.84)\end{array}$ & $\begin{array}{l}0.436^{* *} \\
(2.75)\end{array}$ & $\begin{array}{l}0.447^{* *} \\
(2.76)\end{array}$ \\
\hline Content controls & No & Yes & No & Yes & No & Yes & No & Yes \\
\hline$N$ & 203 & 203 & 210 & 210 & 203 & 203 & 210 & 210 \\
\hline
\end{tabular}

Notes: See Table 2, Levels of statistical significance are ${ }^{*} p<0.05,{ }^{* *} p<0.01$,

${ }^{21}$ We have checked several other potential factors, for which we have data, such as previous internships or vocational training. While those possible admission criteria mostly turn out to be insignificant predictors for graduate student performance, the link between UGPA and the latter is again unaffected by their consideration. 
interest, UGPA. The simultaneous use of both predictors of graduate student performance reveals two findings. With respect to average grades, the relationship is almost as strong between HGPA and GGPA compared to the predictive power of UGPA. So, despite the obvious shortcoming of high school outcomes, that is the large time-lag, the predictive power to explain student success appears to be remarkably consistent. Even more intriguing is the situation regarding the other performance variable. While the above results have shown that UGPA is only a weak predictor of study progress in graduate programmes, the parallel use of both grade point averages in one model clearly underlines the inferiority of the more recent grade outcome. This finding substantiates our fourth hypothesis.

This impressive role of HGPA is remarkable for several reasons. First, there are factors related to the specific high school, which may weaken the predictive power of HGPA just as the predictor UGPA may be plagued by differences in the undergraduate backgrounds of students. Second, the fact that HGPA actually did play a role in the admission procedure and thus in our data also suggests that we rather underestimate its predictive power. To explain why HGPA appears to be a good proxy, despite all these points, we point out that German high school students are not faced with a decision situation where they can choose a slower study progress to increase the probability of grade success. We conclude that performance is measured better by grades when there is no option for students to decide about their study progress. This conclusion also supports studies that make use of high school grades as ability proxies in the context of research in higher education (e.g. de Paola and Scoppa 2010; 2011; Grave 2011; Bratti and Staffolani 2013).

\section{Discussion}

The legal framework in the European education system forces universities to select graduate students on the basis of the UGPA. Therefore, it becomes hard if not impossible for those applicants who aimed their previous efforts on outcomes other than grades to get graduate study places at top universities. While it seems that European universities have received independence in selecting their students as a result of the recent educational reforms, other political ideas such as comparability of degrees across institutions of higher education are the basis for legal restrictions. Such interventions are hard to inspect empirically as existing laws prevent investigation of the counterfactual of what would happen if universities could pick students more freely in the absence of such rules.

Thanks to the availability of data from a large and popular German university that officially acted against the law, we can examine how applicants with rather weak UGPA perform in high-quality graduate studies, for which under the existing circumstances they cannot enrol. In line with our theoretical hypotheses, we find that UGPA does predict academic performance of graduate students satisfactorily as long as the examination is limited to grades as the only performance measure. Considering study progress as a second performance indicator, shortcomings of the predictor and thus the admission criterion UGPA are revealed.

An explanation in our view is the trade-off for students in many countries between faster studying and grade achievement. As a consequence of the given incentive structure that emerged out of the Bologna framework, it is likely that undergraduates put their efforts increasingly into the achievement of better grades and therewith accept longer study time. This adds to the discussion of financial incentives, such as tuition fees (see e.g. Schindler 2011; Kauder and Potrafke 2013; Chapman and Sinning 2014), which dominate the previous research on why students spend too much time in the system of higher education. Extraordinarily high study costs, as in the United Kingdom, constitute one approach to make study delays appear as a rather unattractive option in a student's personal utility calculation.

By ignoring study progress as a factor in the discussion of student selection, universities are less likely to pick the applicants who would match best, while less qualified applicants may outdo those who adhere to the major educational goal of completing the exams in a timely fashion. As a practical suggestion in terms of student admission, our results suggest using UGPA as a criterion, due to its strong power to predict GGPA, but that it should also be combined with other criteria. Final completion time is certainly no perfect measure of performance, as discussed above, but as an admission criterion it may capture some of the variation coming from differences in students' attitudes towards 
speedy studying. Another suggestion derived from our empirical analysis is to consider HGPA. Its predictive power in terms of grades and study progress appears to be strong, despite the large time-lag between high school time and graduate studies. Our results also support the idea that the previously attended school may matter in regard of performance in a master programme, although current law does not allow its use as andmission criterion.

Finally, we surely cannot proof the external validity of our findings from one particular school. Just like other researchers using data from small student cohorts (e.g. Stinebrickner and Stinebrickner 2008b), we wish to mention that we have no particular reason to believe that the problems discussed here are less relevant in other settings, at least with regard to the European system of higher education. We can safely say that, for the faculty at hand, obeying the law would have prevented an admission of students that turned out to be capable of achieving the goal of completing their degree quickly. As it is hardly possible to inspect other datasets with the type of students who were admitted illegally, we believe that our results are informative, despite the obvious concerns when having a small number of students from only one university. Furthermore, our data does not allow the examination of causal determinants of study success, including of course grade average. ${ }^{22}$ Future research may furthermore provide a comprehensive investigation of the impact of the Bologna reforms on study durations, which could verify whether the concerns about the incentive structure described in our article turn out to be well justified.

\section{Disclosure statement}

No potential conflict of interest was reported by the authors.

\section{References}

Aina, C., E. Baici, and G. Casalone. 2011. "Time to Degree: Students' Abilities, University Characteristics or
Something Else? Evidence from Italy." Education Economics 19: 311-325.

Arnold, I. J. M., and J. T. Straten. 2012. "Motivation and Math Skills as Determinants of First-Year Performance in Economics." Journal of Economic Education 43: 33-47.

Avdic, D., and M. Gartell. 2015. "Working while Studying? Student Aid Design and Socioeconomic Achievement Disparities in Higher Education." Labour Economics 33: 26-40.

Beekhoven, S., U. de Jong, and H. van Hout. 2003. "Different Courses, Different Students, Same Results? An Examination of Differences in Study Progress of Students in Different Courses." Higher Education 46: 37-59.

Behr, A., and K. Theune. 2016. "The Causal Effect of OffCampus Work on Time to Degree." Education Economics 24: 189-209.

Blanden, J., and S. Machin. 2013. "Educational Inequality and the Expansion of United Kingdom Higher Education." Scottish Journal of Political Economy 60: 597-598.

Bologna Declaration. 1999. Joint Declaration of the European Ministers of Education.

Borg, M. O., and H. A. Stranahan. 2002. "Personality Type and Student Performance in Upper-Level Economics Courses: The Importance of Race and Gender." Journal of Economic Education 33: 3-14.

Bosshardt, W. 2004. "Student Drops and Failure in Principles Courses." Journal of Economic Education 35: 111-128.

Bound, J., M. F. Lovenheim, and S. Turner. 2012. "Increasing Time to Baccalaureate Degree in the United States." Education Finance and Policy 7: 375-424.

Bratti, M., and S. Staffolani. 2013. "Student Time Allocation and Educational Production Functions." Annals of Economics and Statistics 111/112: 103-140.

Brunello, G., C. Lucifora, and R. Winter-Ebmer. 2004. "The Wage Expectations of European College Students." Journal of Human Resources 39: 1116-1142.

Brunello, G., and R. Winter-Ebmer. 2003. "Why Do Students Expect to Stay Longer in College? Evidence from Europe." Economics Letters 80: 247-253.

Butler, J. S., T. Aldrich Finegan, and J. J. Siegfried. 1994. "Does More Calculus Improve Student Learning in Intermediate Micro and Macro Economic Theory?" American Economic Review 84: 206-210.

Chapman, B., and M. Sinning. 2014. "Student Loan Reforms for German Higher Education: Financing Tuition Fees." Education Economics 22: 569-588.

Confederation of EU Rectors' Conference and Association of European Universities. 2000. "The Bologna Declaration on the European Space for Higher Education: An Explanation." Accessed April 32012 http://ec.europa.eu/education/policies/ educ/bologna/bologna.pdf

\footnotetext{
${ }^{22}$ One could argue that variation in UGPA affects factors such as attention from faculty or more elite classmates, which in turn causally affect study success beyond a student's basic capability to perform well. As our question here is whether the latter is well approximated by UGPA and whether it is therefore a good admission criterion, exogenous variation in UGPA, holding constant all relevant factors, does not help us in addressing our objectives. Nonetheless, the question whether UGPA have a causal impact on study success might certainly be informative when studied in other research contexts, e.g. with respect to the problem of grade inflation (see e.g. Ehlers and Schwager 2016).
} 
de Fraja, G., and P. Landeras. 2006. "Could Do Better: The Effectiveness of Incentives and Competition in Schools." Journal of Public Economics 90: 189-213.

de Paola, M., and F. Gioia. 2017. "Impatience and Academic Performance. Less Effort and Less Ambitious Goals." Journal of Policy Modeling 39: 443-460.

de Paola, M., and V. Scoppa. 2010. "Peer Group Effects on the Academic Performance of Italian Students." Applied Economics 42: 2203-2215.

de Paola, M., and V. Scoppa. 2011. "The Effects of Class Size on the Achievement of College Students." Manchester School 79: 1061-1079.

de Paola, M., and V. Scoppa. 2015. "Procrastination, Academic Success and the Effectiveness of a Remedial Program." Journal of Economic Behavior \& Organization 115: 217-236.

Ehlers, T., and R. Schwager. 2016. "Honest Grading, Grade Inflation, and Reputation." CESifo Economic Studies 62: 506521.

Garibaldi, P., F. Giavazzi, A. Ichino, and E. Rettore. 2012. "College Cost and Time to Complete a Degree: Evidence from Tuition Discontinuities." Review of Economics and Statistics 94: 699-711.

Gary-Bobo, R. J., and A. Trannoy. 2008. "Efficient Tuition Fees and Examinations." Journal of the European Economic Association 6: 1211-1243.

German Council of Science and Humanities [Wissenschaftsrat]. 2004. "Empfehlungen des Wissenschaftsrats zur Reform des Hochschulzugangs vom 30. 1.2004." http://www.wis senschaftsrat.de/texte/5920-04.pdf

Grave, B. S. 2011. "The Effect of Student Time Allocation on Academic Achievement." Education Economics 19: 291-310.

Groen, J. A., G. H. Jakubson, R. G. Ehrenberg, S. Condie, and A. Y. Liu. 2008. "Program Design and Student Outcomes in Graduate Education." Economics of Education Review 27: 111-124.

Helms, R. M. 2008. "University Admission Worldwide." In The World Bank, International Bank for Reconstruction and Development. Washington, DC.

Holmlund, B., Q. Liu, and O. N. Skans. 2008. "Mind the Gap? Estimating the Effects of Postponing Higher Education." Oxford Economic Papers 60: 683-710.

Kauder, B., and N. Potrafke. 2013. "Government Ideology and Tuition Fee Policy: Evidence from the German States." CESifo Economic Studies 59: 628-649.

Kuncel, N. R., M. Credé, and L. L. Thomas. 2007. "A MetaAnalysis of the Predictive Validity of the Graduate Management Admission Test (GMAT) and
Undergraduate Grade Point Average (UGPA) for Graduate Student Academic Performance." Academy of Management Learning \& Education 6: 51-68.

Kuncel, N. R., S. A. Hezlett, and D. S. Ones. 2001. "A Comprehensive Meta-Analysis of the Predictive Validity of the Graduate Record Examinations: Implications for Graduate Student Selection and Performance." Psychological Bulletin 127: 162-181.

Leuven, E., H. Oosterbeek, and B. van der Klaauw. 2010. "The Effect of Financial Rewards on Students' Achievement: Evidence from a Randomized Experiment." Journal of the European Economic Association 8: 1243-1265.

Liu, L., and W. S. Neilson. 2011. "High Scores but Low Skills." Economics of Education Review 30: 507-516.

Machin, S., and P. A. Puhani. 2005. "Special Issue on the Economics of Education - Policies and Empirical Evidence: Editorial." German Economic Review 6: 259-267.

Non, A., and D. Tempelaar. 2016. "Time Preferences, Study Effort, and Academic Performance." Economics of Education Review 54: 36-61.

OECD. 2013. Education at a Glance 2013. OECD Indicators, Paris: OECD Publishing.

Schindler, D. 2011. "Tuition Fees and the Dual Income Tax: The Optimality of the Nordic Income Tax System Reconsidered." German Economic Review 12: 59-84.

Stinebrickner, R., and T. R. Stinebrickner. 2008a. "The Effect of Credit Constraints on the College Drop-Out Decision: A Direct Approach Using a New Panel Study." American Economic Review 98: 2163-2184.

Stinebrickner, R., and T. R. Stinebrickner. 2008b. "The Causal Effect of Studying on Academic Performance." B. E. Journal of Economic Analysis \& Policy 8: Article 14.

Stock, W. A., and J. J. Siegfried. 2006. "Time-to-Degree for the Economics Ph.D. Class of 2001-2002," American Economic Review 96: 467-474.

Stock, W. A., J. J. Siegfried, and T. Aldrich Finegan (2011). Completion Rates and Time-to-Degree in Economics $\mathrm{PhD}$ Programs. American Economic Review: Papers \& Proceedings, 101, 176-187.

Van der Klaauw, B., and A. van Vuuren. 2010. "Job Search and Academic Achievement." European Economic Review 54: 294-316.

Win, R., and P. W. Miller. 2005. "The Effects of Individual and School Factors on University Students' Academic Performance." Australian Economic Review 38: 1-18. 


\section{Appendix}

\section{A1. Theoretical framework}

Suppose first of all that $\delta$ increases. Total differentiation of (9) and (10) yields:

$$
\left(\begin{array}{cc}
U_{e e} & U_{e x} \\
U_{x e} & U_{x x}
\end{array}\right)\left(\begin{array}{l}
d e \\
d x
\end{array}\right)=\left(\begin{array}{c}
-U_{e \delta} d \delta \\
-U_{x \delta} d \delta
\end{array}\right) .
$$

Using Cramer's rule, we obtain

$$
\begin{gathered}
\frac{d e}{d \delta}=\frac{-\underbrace{U_{e \delta}}_{>0} \underbrace{U_{x x}}_{<0}+\underbrace{U_{e x}}_{<0} \underbrace{U_{x \delta}}_{=0}}{\underbrace{|H|}_{>0}}=\frac{\underbrace{U_{e \delta} U_{x x}}_{>0}}{\underbrace{|H|}_{>0}}>0, \\
\frac{d x}{d \delta}=\frac{-\underbrace{U_{e e}}_{<0} \underbrace{U_{x \delta}}_{=0}+\underbrace{U_{e \delta}}_{>0} \underbrace{U_{x e}}_{<0}}{|H|}=\underbrace{\underbrace{U_{e \delta} U_{x e}}_{>0}}_{<0}<0 .
\end{gathered}
$$

Next, we consider an increase in the ability level $a$. Through total differentiation of the first-order conditions, we obtain

$$
\left(\begin{array}{ll}
U_{e e} & U_{e x} \\
U_{x e} & U_{x x}
\end{array}\right)\left(\begin{array}{l}
d e \\
d x
\end{array}\right)=\left(\begin{array}{l}
-U_{e a} d a \\
-U_{x a} d a
\end{array}\right)
$$

Note that the sign of $U_{e a}$ depends on the cross derivations $p_{e a}$ and $q_{e a}$. Intuitively, the increase of both probabilities due to a raise of $e$ should be higher if the student is associated with a high ability level. For simplicity, we assume $p_{e a}=q_{e a}>0$ which yields $U_{e a}>0 .{ }^{23}$ Using Cramer's rule, we get

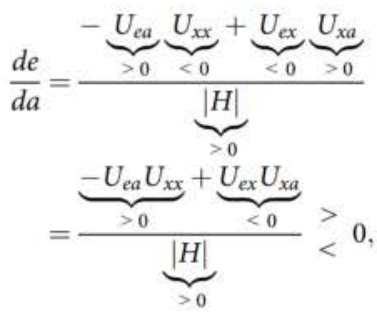

$$
\begin{aligned}
\frac{d x}{d a} & =\frac{-\underbrace{U_{e e}}_{<0} \underbrace{U_{x a}}_{>0}+\underbrace{U_{e a}}_{>0} \underbrace{U_{x e}}_{<0}}{|H|} \\
& =\frac{\underbrace{-U_{e e} U_{x a}}_{<0}+\underbrace{U_{e a} U_{x e}}_{>0}}{|H|}>0 .
\end{aligned}
$$

\begin{tabular}{|c|c|c|c|c|c|c|c|c|}
\hline \multirow{2}{*}{$\begin{array}{l}\text { Method: } \\
\text { Specification: }\end{array}$} & \multicolumn{4}{|c|}{ Standard linear regressions } & \multicolumn{4}{|c|}{ Ordered probit } \\
\hline & (1) & (2) & (3) & (4) & (5) & (6) & (7) & (8) \\
\hline \multicolumn{9}{|c|}{ (a) Performance measure: graduate grades } \\
\hline UGPA & $\begin{array}{l}0.285^{* *} \\
(4.38)\end{array}$ & $\begin{array}{l}0.292^{* *} \\
(4.50)\end{array}$ & $\begin{array}{l}0.376^{* *} \\
(4.87)\end{array}$ & $\begin{array}{l}0.387^{* *} \\
(5.04)\end{array}$ & $\begin{array}{l}0.726^{* *} \\
(4.01)\end{array}$ & $\begin{array}{l}0.756^{* *} \\
(4.15)\end{array}$ & $\begin{array}{l}0.766^{* * *} \\
(4.49)\end{array}$ & $\begin{array}{l}0.803^{* *} \\
(4.67)\end{array}$ \\
\hline Programme fit & & $\begin{array}{c}0.246^{+} \\
(1.76)\end{array}$ & & $\begin{array}{l}0.342^{*} \\
(2.07)\end{array}$ & & $\begin{array}{c}0.746^{+} \\
(1.94)\end{array}$ & & $\begin{array}{l}0.788^{*} \\
(2.22)\end{array}$ \\
\hline Programme dummies & Yes & Yes & Yes & Yes & Yes & Yes & Yes & Yes \\
\hline \multicolumn{9}{|c|}{ (b) Performance measure: graduate study progress } \\
\hline UGPA & $\begin{array}{l}0.498 \\
(0.51)\end{array}$ & $\begin{array}{r}0.480 \\
(0.49)\end{array}$ & $\begin{array}{l}2.069^{+} \\
(1.78)\end{array}$ & $\begin{array}{l}2.110^{+} \\
(1.81)\end{array}$ & $\begin{array}{l}-0.093 \\
(-0.54)\end{array}$ & $\begin{array}{l}-0.093 \\
(-0.53)\end{array}$ & $\begin{array}{c}0.084 \\
(0.51)\end{array}$ & $\begin{array}{r}0.091 \\
(0.55)\end{array}$ \\
\hline Programme fit & & $\begin{array}{l}-0.593 \\
(-0.28)\end{array}$ & & $\begin{array}{l}1.275 \\
(0.51)\end{array}$ & & $\begin{array}{r}0.005 \\
(0.01)\end{array}$ & & $\begin{array}{c}0.227 \\
(0.65)\end{array}$ \\
\hline Programme dummies & Yes & Yes & Yes & Yes & Yes & Yes & Yes & Yes \\
\hline$N$ & 203 & 203 & 210 & 210 & 203 & 203 & 210 & 210 \\
\hline
\end{tabular}

\section{A2. Empirical analysis}

Table A1. Descriptive information ( $N=210$ observations).

\begin{tabular}{lrrrc}
\hline Variable & Mean & SD & Min & Max \\
\hline Performance outcomes & & & & \\
Graduate grade point averages (GGPA) & 2.31 & 0.52 & 1.27 & 4 \\
Graduate credit points & 24.96 & 7.54 & 0 & 37.5 \\
Performance predictors & & & & \\
Undergraduate grade point average (UGPA) & 2.08 & 0.48 & 1 & 3.3 \\
Undergraduate completion time & -0.27 & 0.70 & -5 & 1 \\
University & 0.84 & 0.37 & 0 & 1 \\
College & 0.09 & 0.28 & 0 & 1 \\
Academy & 0.02 & 0.14 & 0 & 1 \\
School abroad & 0.06 & 0.23 & 0 & 1 \\
Same university & 0.48 & 0.50 & 0 & 1 \\
Undergraduate-graduate programme fit & 0.70 & 0.46 & 0 & 1 \\
Vocational training & 0.11 & 0.32 & 0 & 1 \\
Number of internships & 1.58 & 1.24 & 0 & 5 \\
High school grade point average (HGPA) & 1.95 & 0.49 & 1 & 3.7 \\
Female & 0.41 & 0.49 & 0 & 1 \\
Age & 23.58 & 1.43 & 21 & 33 \\
\hline
\end{tabular}

Table A2. Undergraduate grades, study programme and graduate student performance.

Notes: See Table 2. Programme dummies reflect all study programmes, for which there are at least four observations. Levels of statistical significance are ${ }^{+}$ $p<0.1,{ }^{*} p<0.05,{ }^{* *} p<0.01$.

${ }^{23}$ In the special case of $p_{e a}=q_{e a}=0$, we still obtain $U_{e a}>0$ since the marginal disutility of $e$ is decreasing in $a$. 
Table A3. High school grades and graduate student performance.

\begin{tabular}{|c|c|c|c|c|c|c|c|c|}
\hline \multirow{2}{*}{$\begin{array}{l}\text { Method: } \\
\text { Specification: }\end{array}$} & \multicolumn{4}{|c|}{ Standard linear regressions } & \multicolumn{4}{|c|}{ Ordered probit } \\
\hline & (1) & (2) & (3) & (4) & (5) & (6) & (7) & (8) \\
\hline \multicolumn{9}{|c|}{ (a) Performance measure: graduate grades } \\
\hline HGPA & $\begin{array}{l}0.240^{* *} \\
(4.07)\end{array}$ & $\begin{array}{l}0.251^{* *} \\
(4.17)\end{array}$ & $\begin{array}{l}0.302^{* *} \\
(4.30)\end{array}$ & $\begin{array}{l}0.302^{* *} \\
(4.18)\end{array}$ & $\begin{array}{l}0.546^{* *} \\
(3.33)\end{array}$ & $\begin{array}{l}0.577^{* *} \\
(3.46)\end{array}$ & $\begin{array}{l}0.576^{* *} \\
(3.75)\end{array}$ & $\begin{array}{l}0.593^{* *} \\
(3.78)\end{array}$ \\
\hline Content controls & No & Yes & No & Yes & No & Yes & No & Yes \\
\hline$N$ & 203 & 203 & 210 & 210 & 203 & 203 & 210 & 210 \\
\hline (Pseudo) $R^{2}$ & 0.076 & 0.090 & 0.082 & 0.086 & 0.020 & 0.025 & 0.023 & 0.025 \\
\hline HGPA & $(2.65)$ & $(2.71)$ & $(3.17)$ & $(2.80)$ & $(2.49)$ & $(2.86)$ & $(2.97)$ & $(3.01)$ \\
\hline Content controls & No & Yes & No & Yes & No & Yes & No & Yes \\
\hline$N$ & 203 & 203 & 210 & 210 & 203 & 203 & 210 & 210 \\
\hline (Pseudo) $R^{2}$ & 0.034 & 0.231 & 0.046 & 0.189 & 0.012 & 0.072 & 0.015 & 0.059 \\
\hline
\end{tabular}

Notes: See Table 2 . Levels of statistical significance is ${ }^{* *} p<0.01$. 